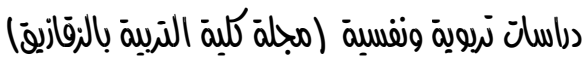

\title{
English for sustainable development integration: A transformative curriculum framework
}

\author{
Dr Samia Kara \\ English and Scientific Method Department, the German University in \\ Cairo, Egypt
}

Email: samia.kara@guc.edu.eg

\begin{abstract}
:
As much as it has benefited them, science has also harmed humans. Indeed, mother earth is suffering altogether with its inhabitants from the abuse they have been subject to. To grant all their recuperation right and to preserve the future generations' existence one, education for sustainable development stands as a firm need; and the realm of English teaching constitutes a valuable resource for concept attainment. This paper offers a transformative curriculum framework to be used by curriculum developers and textbook writers for the sake of integrating sustainable development concepts via the reading skill. Meant to be suitable to any English course at any level and in any context, it incorporates sustainable development goals and competencies as well as concept oriented reading instruction dimensions and strategies.
\end{abstract}

Keywords: Sustainable development, Concept oriented reading instruction, Curriculum framework, English teaching.

اللفة الإنجليزية من أجل التنمية المستدامة : إطار تحويلي للمناهج

المالغص:

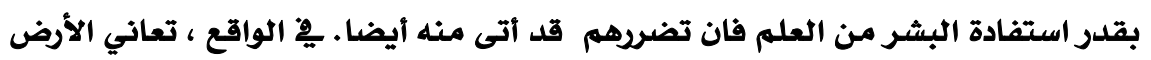

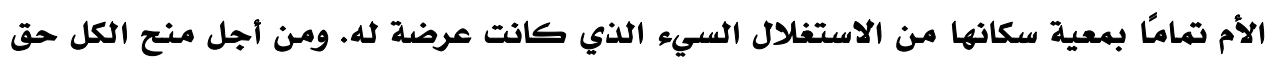

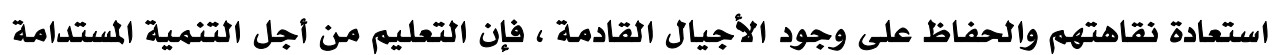




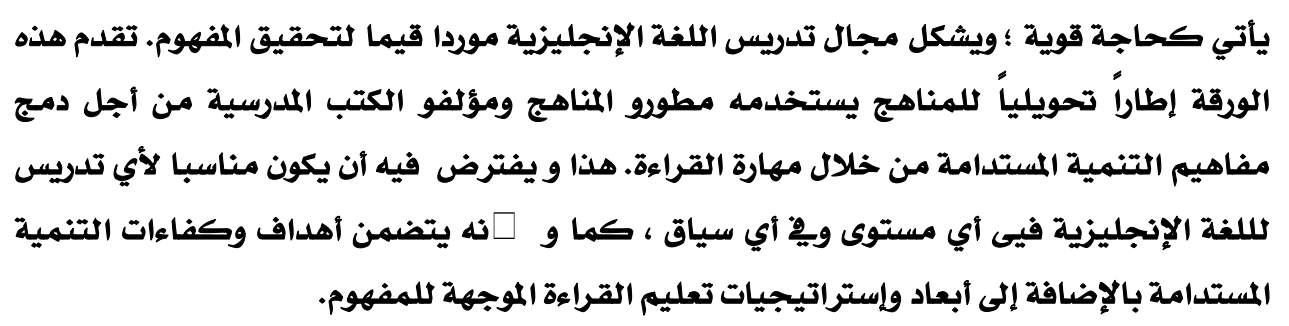

الكلمات المفتاحية: التنمية المستدامة ، تعليم القراءة الموجهة للمفهوم ، إطار المناهج ، اللغة

الإنجليزية

\section{Introduction}

Science has propelled humanity towards prosperity very rapidly. History books do tell us about miseries before Alexander Fleming's penicillin, Louis Pasteur's vaccination and Gregor Mendel's genetics to name a few. However, as much as it has helped humans to build their future, it has also helped them to program their own annihilation. Mass destruction arms, genetic manipulations, overconsumption of natural resources, land and water pollution, greenhouse gases and many other calamities have punctuated modern life with thousands of incidents, wars and deceptions. Thus, in the name of life saving, science has harmed the very essence of life itself. A case in point is the use of pesticides which were supposed to increase 


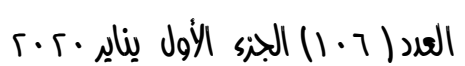

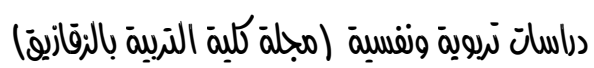

the produce and which, in fact, are decreasing them because they are killing pollination agents like bees.

Since the protection of the environment lies at the heart of the protection of life in all its diverse forms, it has become a necessity not only to be aware of the gravity of the situation created on earth, but also to learn and to teach how to be aware of it. Another obligation comes in relation to learning how to remedy the problem through initiatives globally agreed on in terms of sustainable development. The said initiatives that are meant to be concretised at the decision makers' soonest possible also entail an engagement in futuristic scopes of which education is an important ingredient.

Education for sustainable development is today taking more and more importance as to quality and lifelong learning; and it is but normal that teaching English as a first, second or foreign language should be part of it. This article proposes a transformative framework to be used by curriculum developers and textbook writers for the sake of integrating sustainable development concepts via the reading skill in any English course at any level and in any context. The framework combines 
sustainable development goals and competencies and concept oriented reading instruction dimensions and strategies.

\section{Literature Review}

\subsection{Education for sustainable development}

The definition of sustainable development (SD) - by the Brutland commission in 1987- and which conceptualised its goal in terms of realising the present generations' needs without depriving the future generations of meeting their own, was left expansive on purpose to guarantee enough room for interpretations that suit specific contexts, and to counteract the criticism of SD as being indoctrinating by nature regarding its clear adoption of values (Dale and Newman, 2006). One of the conflicting interpretations of the aforementioned definition is the fact that it gathers two opposite goals: sustainment vs. development (Corney, 2006). In other words, what might be questioned is the humans' ability to meet their present necessities and development without compromising future generations' needs, especially that they may not be able to define these needs. In its Resolution $\mathrm{A} / \mathrm{RES} / 70 / 1$ of 25 September 2015, the United Nations General Assembly came up 
with a set of 17 SD broad goals that encompass 169 targets and 241 indicators and which constitute the transformative 2030 Agenda agreed on by 169 countries (UN, 2018). These goals are:

- No poverty

- Zero hunger

- Good health and well-being

- Quality education

- Gender equality

- Clean water and sanitation

- Affordable and clean energy

- Decent work and economic growth

- Industry, innovation and infrastructure

- Reduced inequality

- Sustainable cities and communities

- Responsible consumption and production

- Climate action

- Life below water

- Life on land

- Peace and justice strong institutions

- Partnerships to achieve the goal (UN, 2018). 
One way to approach these goals is via education. Correspondingly, relating education to SD goals takes the complexity of the Brutland commission definition further as education itself is perceived differently by different ideologies (Corney, 2007). However and what is basically agreed on is that 'in the same way that education is key for achieving economic development, it is also essential for achieving sustainable development' (Warland \& Mader, 2015, p.5).

At the very basis of the notion of education for sustainable development (ESD) is the one of the environment. Thus, it is but normal to think of ESD as a natural evolution of environmental education (EE). EE itself is not a new concept; it goes back to Rousseau $(1762$, p.8) who complained about the things that God had perfectly created but which degenerated in the hands of man who forces a land to nourish the productions of another one, a tree to bear the fruits of another; who confounds climates, elements, seasons; who mutilates his dog, his horse, his slave; who upsets everything; who disfigures everything; who likes deformity and monster (Author's translation). Rousseau (1852) carried on pleading for an education that restores the principles of nature since the latter 


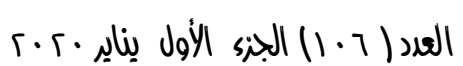

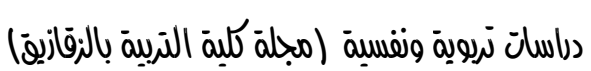

does no longer exist in connection with civilisation. Later on, several attempts were made to delimit the scope of this education that caters for the nature/environment.

The EE goals as stated by the Tbilissi Declaration (1978, p.26) are:

- 'to foster clear awareness of, and concern about, economic, social, political and ecological interdependence in urban and rural areas;

- to provide every person with opportunities to acquire the knowledge, values, attitudes, commitment and skills needed to protect and improve the environment; and

- to create new patterns of behaviour of individuals, groups and society as a whole towards the environment'.

Since the keyword is 'environment', how the latter is viewed shall make the focus of EE. On the strength of Sauvé (1996, pp. 10-13), the environment is viewed as:

- a pure nature that must receive enough interest in terms of appreciation, respect and preservation;

- a resource that is decaying and which is in need of management; 
- a problem that endangers life itself and which needs solutions;

- a living place that includes humans, societies, cultures, technology and history, and which needs to be known, learnt about, planned for and taken into consideration;

- a biosphere that should be nurtured by solidarity among peoples;

- a community project that is shared by all humans and which needs the involvement of everybody.

These conceptions exist synchronously and are not mutually exclusive albeit they are also diachronic in the sense that they came as a consequence of progress (Sauvé, 1996). Thus, the act of educating for the sake of the environment should be viewed in terms of recognising this environment with all its characteristics and problems. To do this, three pathways are to be followed: making the world exist, making the others exist in the world and moving from the 'object world' to the 'project world' (Meirieu, 2001, pp. 9-12). To make the world exist, the focus should be on its concreteness and diversity to face the invading virtual sphere of today's children; and to make the others exist in this world means to construct the basic distinction 


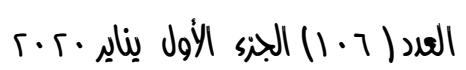

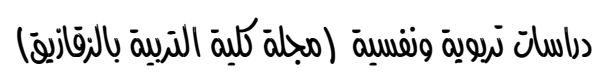

between the private space and the public one (Meirieu, 2001). Finally, to move from the 'object world' to the 'project world' means to transform a child from the condition of a consumer who desires to the one of a researcher who works, uses his/her imagination and makes his/her findings available to everybody (Meirieu, 2001).

The association between EE and SD followed two routes: EE for SD wherein SD is the final outcome, and EE and SD wherein SD goals are to be added to those of EE (Sauvé, 1996). The emergence of ESD came with the report made by the world commission on environment and development in 1987 and which was shouldered by the Rio de Janeiro conference on environment and development in 1992 as well the Johannesburg world summit on SD in 2002 (Jickling \& Wals, 2008).

As ESD targets social transformation, it is comprehended as a fundamental component of a quality education and life learning (Rieckman, 2018) whose main goal is embodied in what Wals (2015; cited in Rieckman, 2018) and Wals \& Lenglet (2016; cited in Rieckman, 2018) called 'sustainability citizens'. Transformative ESD acts in four areas, namely, better quality basic education, adaptation of present curricular to meet sustainability, as well as pursuing public understanding and 
awareness in relation to sustainability (UNESCO, 2012). In addition, and as it is multidisciplinary, it embraces the SD values and encloses the dimensions of environment, society and economy (UNESCO, 2012). It also targets active learning and higher thinking skills, in addition to life-long and formal/ informal/non-formal learning, cultural appropriateness and local needs, contextualised and glocal issues based content, as well as sustainability civil capacity.

In terms of perspectives, ESD can be learner - oriented (learning arises from learners' experiences and questions), process - oriented (focus is on solving problems and considering different opinions democratically), linked to society and nature (learners are involved in life situations and normal societal processes), integrated (including different subjects and perspectives) and related to the notion of the school as a learning environment (Jutvik \& Liepina, 2018, p.27).

A more emancipatory approach to ESD advocates the existence of competencies to be attained (Rieckmann, 2018). These have been delineated by different bodies in terms of different foci. For example, The OECD (2005) came up with its 'Definition and Selection of Competencies (DeSeCo)' Project's 


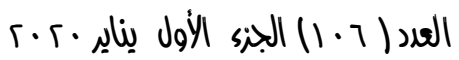

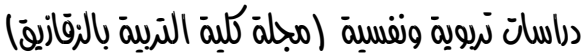

key competencies categorised in three comprehensive categories: using tools (such as language and technology), interacting in heterogeneous groups (with other people of different backgrounds), and acting autonomously. Building on the aforementioned DeSeCo project, the OECD (2018) and within the scope of its 2030 learning framework added three transformative competencies, namely: creating new value, reconciling tensions and dilemmas and taking responsibility.

Another case in point is that of Rieckmann (2018, p. 44) who specified the competencies in terms of:

- Systems thinking: assimilating connections among different systems,

- Anticipatory competency: comprehending possible, probable and desirable futures,

- Normative competency: negotiating sustainability in a context of conflicts of interests,

- Strategic competency: utilising innovative actions that advance sustainability,

- Collaboration competency: facilitating collaborative and participatory problem-solving,

- Critical thinking competency: for the sake of taking a position in the sustainability discourse, 
- Self-awareness competency: in relation to one's own role in the glocal community, and

- Integrated problem-solving competency: application of diverse problem-solving frameworks to multifarious sustainability problems.

\subsection{Concept oriented reading instruction}

The idea of knowledge has all the time been closely linked to the complex reading skill. In fact, the more people read the more knowledge attainment they reach. In addition and unlike speech and language comprehension-which have their own specialised cortical centres, reading is not pre-wired in the brain. Indeed, brain imaging shows that it is 'a three-ring cortical, sub-cortical, mid-brain, and cerebellar parallel processing act, which makes biologically novel use of no fewer than seventeen regions in the brain and integrates them in milliseconds' (Jack, 2010, p. 27). Thus and at the very heart of reading comprehension, there lies the cognitive concept of knowledge transfer and utilisation which takes us back to the basic functions of the brain as a processor that makes learning occur through the organisation of stimuli to which it is exposed. This organisation involves information sifting, selection, storage and use; and specifically, 


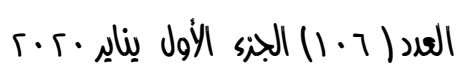

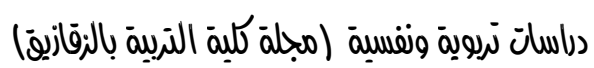

presupposes the existence of an input (in our case, language) in the form of incoming data that would go through the processor / brain to be interpreted and processed into an output (Malim and Cheyne, 1999). When, two or more tasks are processed simultaneously and in parallel- such as learning English and SD values at the same time- this situation is called 'parallel processing'. One way of enhancing the brain to fulfil its parallel processing function in relation to reading is the use of the Concept Oriented Reading Instruction (CORI). Thus, CORI shall be the means by which SD shall be incorporated in an English course.

CORI is a classroom context created for the sake of literacy engagement (Guthrie \& Anderson, 1996). The latter presupposes the existence of an intrinsic motivation which drives the reader, that is the learner, to read for concept attainment and understanding. In other words, the reader focuses on meaning construction through referential representation rather than vocabulary identification (Just and Carpenter, 1987, cited by Boulware and Crow, 2008). The said construction relies heavily on concepts which are mental images the brain forms and stores about categories in the world and which are formed when reason is linked to the perceptual outcomes of senses 
(Prinz, 2004). They are characterised by being sensory or abstract, bearing intentionality, being co-referential but different or divergently referential but alike, and being acquired both ontogenetically and phylogenetically (Prinz, 2004). Concepts play an important role in cognition because they constitute the final outcome of human language as well as thought development.

Accordingly, reading comprehension and in light of CORI is seen as consisting of "the processes of constructing conceptual knowledge from a text through cognitive interaction and motivational involvement with the text' (Guthrie \& Scafiddi, 2004, p.193). This means that there is an involvement that is not only linguistic but also cognitive and which builds up the learner's knowledge at a deeper level. The building up of knowledge is made possible thanks to prior knowledge activation (Guthrie \& Scafiddi, 2004). Thus, if a good amount of knowledge constructed from reading is new, then, this means that learning from a text has taken place as opposed to comprehending a text in the case of a small proportion (Guthrie \& Scafiddi, 2004, p.194). 


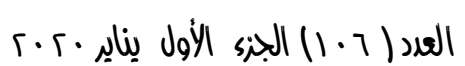

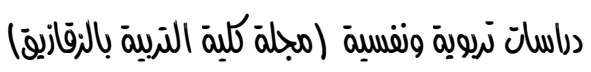

In terms of dimensions, Guthrie et al. (1998, pp. 262-264) described CORI as:

- Observational: Learners observe the world around them in terms of facts and events.

- Conceptual: Learners build up their conceptual knowledge about a particular theme that came out of their observations, through retrieving data from various texts.

- Self-directed: Learners choose their own criteria for their concept attainment in relation to the theme they explore.

- Strategic: Learners learn how to search for sources as well as how to synthesize information using specific and appropriate strategies.

- Collaborative: Learners take part in whole class interactions, collaborative teams, pairs and individual work.

- Self-expressive: Learners express their conceptual understanding through the organization of their information in the form of verbal (presentations) and nonverbal (essays) expression.

- Coherent: Teachers achieve coherence by knitting together activities, materials and contexts that enable students to make connections. 
Taken from the brain parallel processing perspective, these dimensions are realised simultaneously.

CORI is also to be seen in terms of comprehension strategies. Guthrie \& Taboada (2004, pp. 78-83) suggested the following ones:

- Activating background knowledge,

- Questioning in reading,

- Searching for information,

- Summarising during reading,

- Organising graphically, and

- Structuring stories.

\subsection{Curriculum framework}

To define a curriculum framework, the International Bureau of Education - IBE- (2017) suggested that it gets differentiated from the curriculum itself. Indeed, what a curriculum framework does is setting 'parameters, directions standards for curriculum policy and practice' (IBE, 2017, p.6). Thus, if a curriculum is mainly about content, the framework is about how this content is to be developed. 
IBE (2017, p. 6) also maintained that the goals of a curriculum framework are:

- To provide learning opportunities of the highest quality to students.

- To confront and solve problems authorities might face while working on achieving the first goal.

For these goals to be achieved, the framework should be planned and systematic, comprehensive, informed, targeted, broadly supported by concerned bodies as well as inclusive of all stakeholders (IBE, 2017, pp. 7-8). It should also follow a 5 stage process:

- Evidence gathering whereby clear reasons for designing the framework are explained,

- Preparation in relation to how and how long shall the framework take to get developed,

- Development,

- Implementation, and

- Evaluation and monitoring (IBE, 2017, p.9).

2. Curriculum framework for SD concept attainment reading integration

\subsection{Background}


The purpose of the present framework is to provide guidance for curriculum developers and textbook writers who wish to target SD values in relation to English (be it a first, second or foreign language). It is understood that it is not a static entity, nor is it a final document. It might be subject to amendments and should be perceived as a self-updating and flexible processor of needs that are tuned to contexts. It, in particular, stresses the importance of both SD and CORI as vehicles of transformational ESD implementation in the field of teaching English at any level.

\subsection{Structure}

As shown in figure1, the framework is made of three stages, namely, conceptualisation, planning and development. Of course, these stages should be preceded by data gathering and followed by evaluation.

Figure1. Curriculum framework for SD concept attainment reading integration 


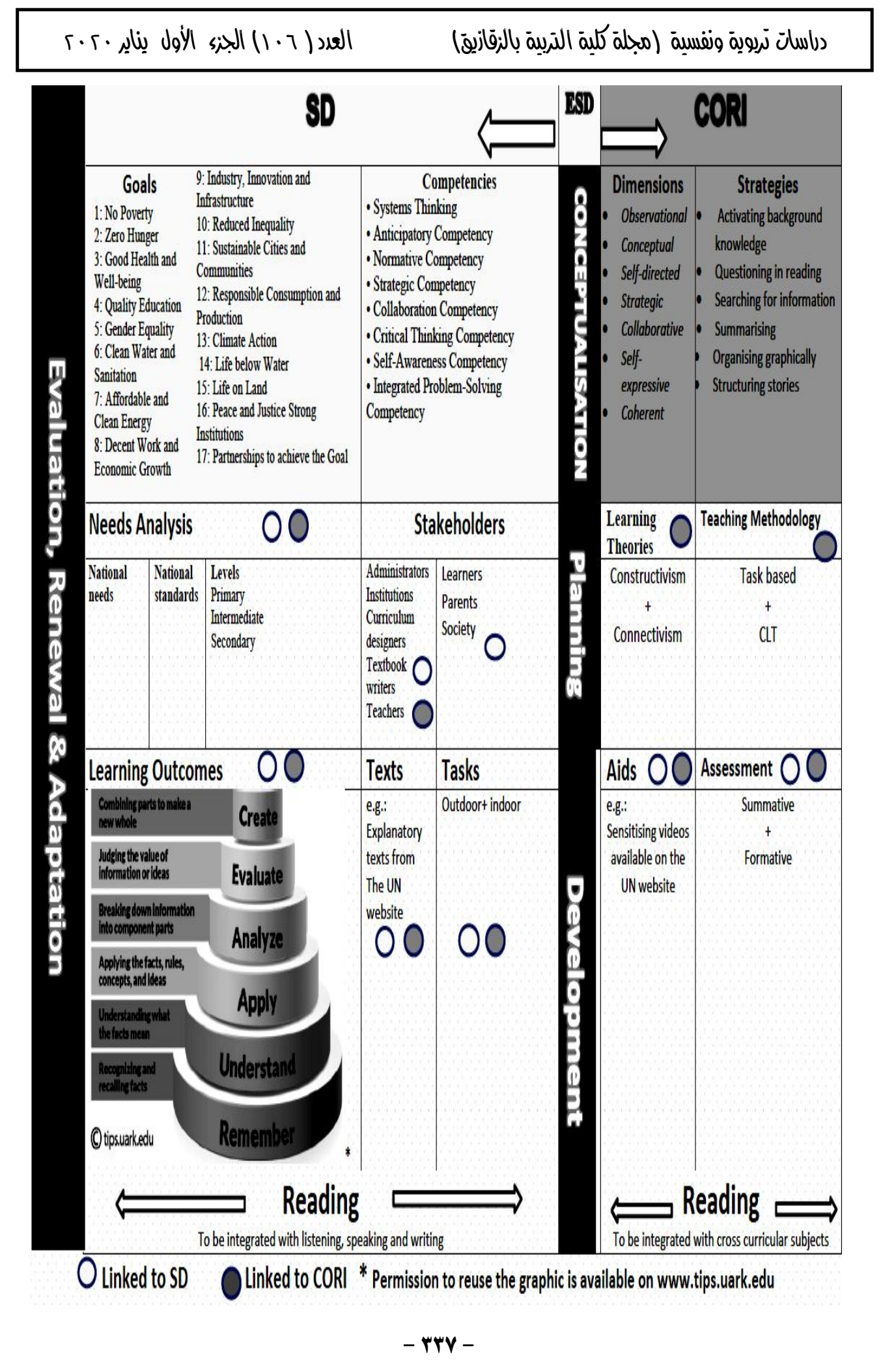




\subsubsection{Conceptualisation}

In the conceptualisation phase, the users are guided towards SD in terms of goals and competencies and towards CORI with regard to dimensions and strategies. The assimilation of these elements will pave the way for the theoretical background of the framework. Firstly, SD goals- and as explained earlier in the literature review, represent the source for topic selection following the local needs, standards and levels. The competencies for their part might be seen in relation to the learners' specifications.

As to CORI, the users explore its dimensions that are interwoven with SD competencies. They also come across its strategies that will serve SD goals as to approaching the texts which are in connection with the selected goals.

After curriculum designers and textbook writers are trained in the gist of SD and CORI and in how they could manage to create links between the two entities, they move to the second stage which is that of planning.

\subsubsection{Planning}

In the planning stage, four entities are to be consulted. The first one is 'Needs Analysis' whereby a thorough scrutiny 


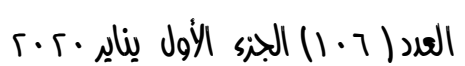

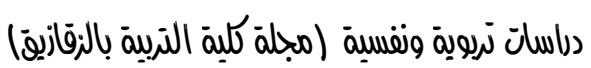

of the learners' requirements is made taking into account the predefined national needs, national standards and learners' levels. In case environmental issues already existed before as part of standards in other subjects like biology, they can be reused to select the goals and refine the competencies and dimensions.

The second entity that will receive importance in relation to planning is 'Stakeholders' wherein administrators, institutions, curriculum designers, textbook writers and teachers on one hand as well as learners, parents and society on the other one are consulted and involved. For example, a list of topics derived from goals can be made and sent to parents and learners to select from. Teachers and school administrators will be approached for the same task in addition to a required selection from CORI strategies by virtue of their experiential knowledge of the latter's degree of feasibility.

Fourthly, there comes the third entity which is that of 'Learning Theories'. Learning theories facilitate the selection of the right competency and strategy as per learners' characteristics. For instance, the strategy of activating background knowledge is linked to constructivism whereas the one of searching for information is related to connectivism. 
Finally, there comes 'Teaching Methodology'. Here, it is advisable for the framework users to be eclectic and choose approaches and methods that go along with both learning theories and contexts.

\subsubsection{Development}

At this stage, learning outcomes are adapted to goals, competencies, dimensions and strategies. They are also expressed in terms of bloom's taxonomy as per national groupings. Then, texts are selected and the UN website can serve as a valuable source. For their part, tasks are chosen and aligned with strategies and can be both outdoor and indoor. For instance, if the goal is 'life on land' and the topic is 'biodiversity', a trip can be organised to a zoo where primary school learners are introduced to different types of animals. The discussion of what they saw shall activate their prior knowledge before they start reading a text on biodiversity in class. For their part, teaching aids can be varied and again the UN website has its own videos. Finally, the assessment can be summative, that is at the end of the unit, or formative (for instance, writing reports). 
All these elements come under the umbrella of reading. However, reading itself should be integrated with the other skills as well as cross curricular subjects. In addition, the whole process shall be subjected to evaluation, renewal and adaptation.

\subsection{Usability}

Taking into account the flexibility feature, figure 2 shows that the framework usability is subject to a set of situations. Indeed, it can be used when a curriculum is newly designed, renewed or adapted. This use can be at the planning, development, implementation or evaluation stage. In addition, the framework can be used in its whole entity to develop the whole of a curriculum or as a whole to develop a part of the curriculum. In case some parts only are needed from the framework, it can be used as a part to develop a part of the curriculum or as a part to develop the whole curriculum. Finally, the contexts for its use are those of first language, second language and foreign language.

\section{Figure 2: Framework usability}




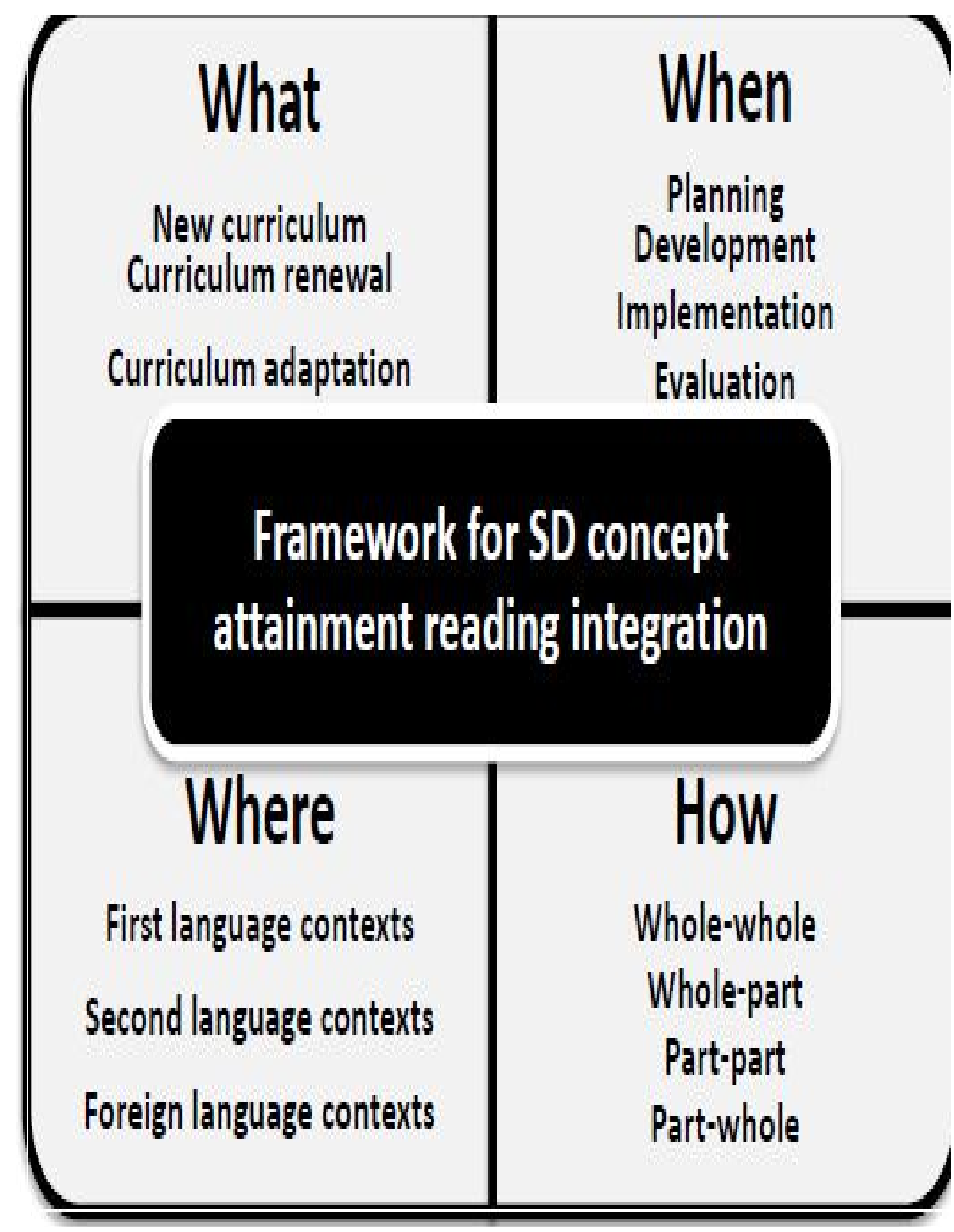




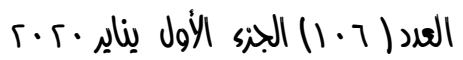

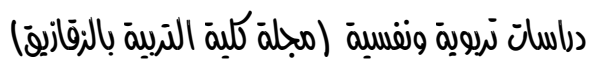

\subsection{The framework as a learning cycle}

Because a framework is an intellectual activity that presupposes the presence of learning processes, Kolb's (1984) learning cycle encompasses the needed stages for any further developments. Indeed and as displayed in figure 3, the framework starts being used (concrete experience), then, observations and reflections are made on its use (reflective observation). These observations and reflections will be used to analyse its effects and draw conclusions (abstract conceptualisation). Finally, the aforementioned conclusions are used to test hypotheses for future framework adaptations (active experimentation).

\section{Figure 3: The framework as a learning cycle}

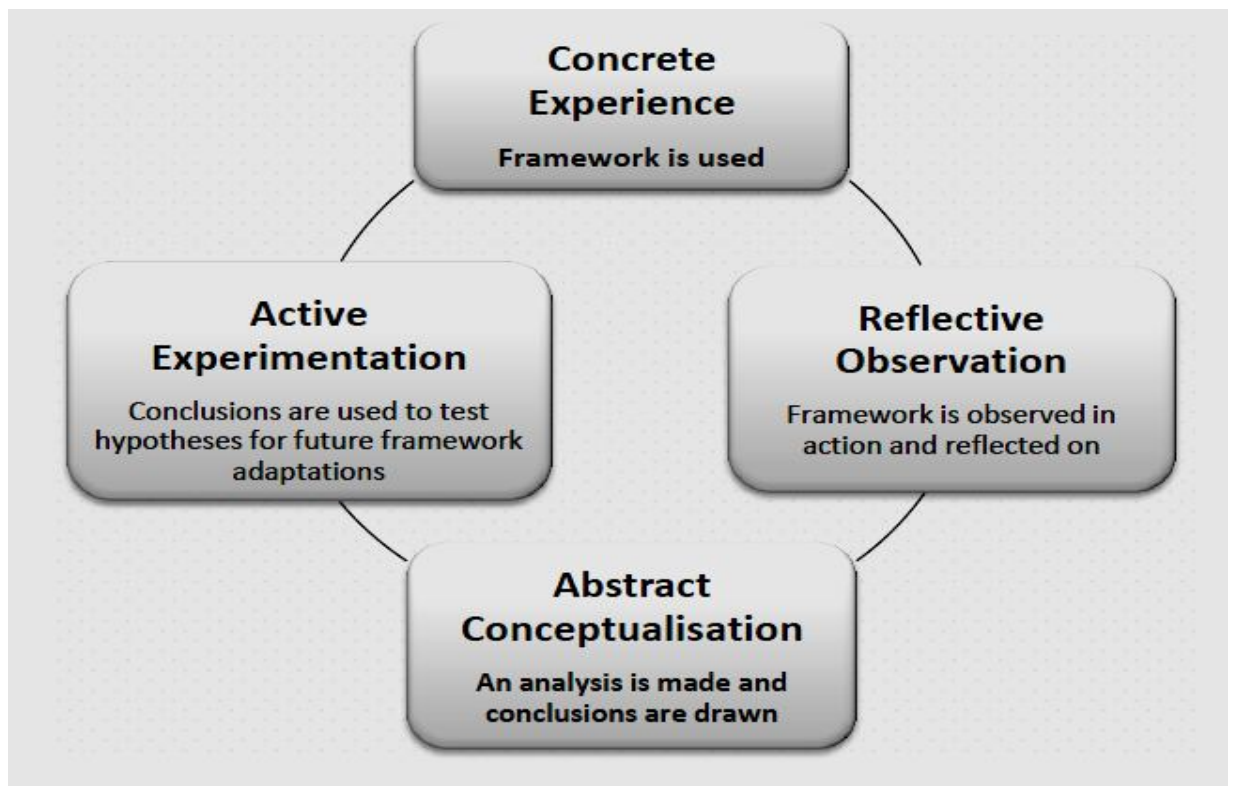




\subsection{Non-formal learning outcomes}

Framework users should bear in mind that whilst selecting from SD competencies and CORI dimensions, there are non-formal learning outcomes to be taken into account. In fact and because learners need to be connected with their environment, Meirieu's (2001) abovementioned pathways can be enlivened. For instance, combining the CORI observational and coherent dimensions with the SD systems thinking competency serve the pathway of making the concrete and diverse world exist. If the CORI collaboration dimension and the SD collaborative and strategic competencies are added, the 'others' are made existing in this world. The rest of competencies and strategies will serve the third pathway of moving the learner towards a project world. Eventually, these pathways will ingrain lifelong values, attitudes and skills in favour of SD.

\section{Conclusion}

To be able to slow down-if not stop, massive human and environmental destruction, reason clearly stipulates that there is no way other than adopting an engaged positive endorsement of SD principles and practices. Therefore and if world scale meetings, resolutions and treaties are being ratified by nations and largely publicised, work on people as individuals who are members in communities must be performed. In other words, a real transformation in thinking, behaving and valuing must take 
place in the minds of those who will shape the future of mother earth. This is precisely the mission educationists should take to heart for it is through education and training that SD will come true. It will also be seen to blossom and change into the state of global citizenship responsibility.

Within the scope of English teaching and relying on the parallel processing capacity of the brain, this article has proposed a transformative framework for the sake of incorporating SD in curricular of different types and levels. At the very basic echelon, it sought to aid young learners get grips with the notion of sustainability; and at a more cutting-edge stage, it was meant to be an empowering tool for future world citizens to take action both locally and globally.

Of course, it goes without saying that this framework is not the magic wand educationists might make use of to reach $\mathrm{SD}$ as a planetary goal. However and since transformation is a matter of trial and error, the framework relies on core competencies and strategies to bridge the gap between ESD and teaching English as a first, second and foreign language. More precisely, it should be conceived of as a roadmap for future attempts. The latter might include larger perspectives in relation to strategic plans that are to be customised to specific countries and contexts, more consultation strategies with governments, and more organisational involvement. This being said, the ultimate target is to reach an SD scope that is far beyond declarative knowledge and which calls for more process oriented approaches. 


\section{References}

Boulware, J. B. and Crow, M. L. 2008. Using the concept attainment strategy to enhance reading comprehension. The reading Teacher, 61(6), 491- 495. International Reading Association.

Corney, G. 2006. Education for sustainable development: An empirical study of the tensions and challenges faced by geography student teachers. International Research in Geographical and Environmental Education, 15 (3), 224-240.

Dale, A. \& Newman, L. 2006. Sustainable development education and literacy. International Journal of Sustainability in Higher Education, 6(4), 351-362.

Guthrie, J. T. \& Anderson, E. 1996. Teaching with CORI: taking the big jump. NRRC. 1-3.

Guthrie, J. T. \& Scafiddi, N. T. 2004. Reading comprehension for information text: Theoretical meanings, developmental patterns, and benchmarks for instruction. In Wigfield, A. Motivating Reading Comprehension: Concept-Oriented Reading Instruction. 192-211.

Guthrie, J. T. \& Tabaoda, A. 2004. Fostering the cognitive strategies of reading comprehension. In Wigfield, A. Motivating Reading Comprehension: Concept-Oriented Reading Instruction. 75-95.

Guthrie, J. T. Van Meter, P. Hancock, G. R. Alao, S. Anderson, E. and McCann, A. 1998. Does concept- oriented reading instruction increase strategy use and conceptual learning from text? Journal of Educational Psychology, 90(2), 261-278. American Psychological Association, Inc.

International Bureau of Education. 2017. Training tools for curriculum development: Developing and implementing curriculum frameworks. UNESCO.

Jack, C. D. 2010. Exploring brain-based instructional practices in secondary education classes. Unpublished PhD Thesis. Boise State University.

Jickling, B. \& Wals, A. E. J. 2008. Globalisation and environmental education: Looking beyond sustainable development. Journal of Curriculum Studies, 40 (1), 1-21. 
Jutvik, G. \& Liepina, I. 2018. Education for change: A handbook for teaching and learning sustainable development. Baltic University Press. Retrieved on April 1, 2018 from http:www.2. balticuniv.uu.se/index.php/teaching.materials/85/

Kolb, D. A. 1984. Experiential Learning: Experience as the Source of Learning and Development. Englewood Cliffs, N.J: Prentice Hall.

Malim, T. \& Cheyne, S. 1999. Attention and performance limitations. In Taylor, I. (Ed) Active Psychology, pp. 671-712. OUP.

Meirieu, P. 2001. Éduquer à l'environnement : pourquoi ? comment ? Du monde-objet au monde-projet. In Planet'ERE 2: Actes du Deuxième Forum Francophone International de L'éducation à L'environnement, Paris, UNESCO, 21-23 November 2001.

OECD. 2005. Definition and selection of key competencies: executive summary. OECD, Paris. Retrieved on May 5, 2018 from: http://www.oecd.org/dataoecd/47/61/35070367.pdf

OECD. 2018. The future of education and skills education 2030. OECD, Paris.

Prinz, J. J. 2004. Furnishing the mind: concepts and their perceptual basis. OUP.

Rieckmann, M. 2018. Learning to transform the world: Key competencies in education for sustainable development. In Leight, A., Heiss, J. \& Byun, J.W. (eds.). Issues and Trends in Education for Sustainable Development. UNESCO.

Rousseau, J.J. 1762. Émile ou de l'éducation : livres I, II et III. Retrieved from

http://classiques.uqac.ca/classiques/Rousseau_ji/emile/emile_de education 1_3.pdf on May 30, 2018.

Sauvé, L. 1996. Environmental education and sustainable development: A further appraisal. Canadian Journal of Environmental Education,1, 7-34.

UN. 2018. Sustainable development goals. Retrieved on May 5, 2018 from: https://sustainabledevelopment.un.org/resources/publications

UNESCO. 2012. Education for sustainable development sourcebook. UNESCO, Paris.

Warland, L. \& Mader, C. 2015. From global programs on ESD to local implementation in higher education. In Mader, C., Warland, L. \& Hilty, L. eds. Handout Series: Enabling Leadership for Transformational Teaching for Sustainable Development. Sustainability Team, University of Zurich. 